\title{
RESPON MASYARAKAT TERHADAP IMPLEMENTASI SISTEM VERIFIKASI \\ LEGALITAS KAYU DI KELOMPOK TANI MAKMUR DESA TOTOPROJO KECAMATAN WAY BUNGUR KABUPATEN LAMPUNG TIMUR
}

\section{COMMUNITY RESPONSE TO THE IMPLEMENTATION OF TIMBER LEGALITY VERIFICATION SYSTEM IN TANI MAKMUR GROUP TOTOPROJO VILLAGE WAY BUNGUR SUB DISTRICT EAST LAMPUNG DISTRICT}

By :

\author{
Gilang Ekselsa, Slamet Budi Yuwono dan Rudi Hilmanto \\ Jurusan Kehutanan, Fakultas Pertanian, Universitas Lampung \\ Jln. Soemantri Brojonegoro No. 1, Bandar Lampung \\ E-mail: gilangekselsa.ge@,gmail.com \\ Nomor Telepon : 081997562519
}

\begin{abstract}
ABSTRAK
Tingkat kesiapan pengetahuan tentang pelaksanaan Sistem Verifikasi Legalitas Kayu (SVLK) pada saat ini masih sangat terbatas, begitu pula dengan keuntungan dan kerugian SVLK bagi petani Hutan Rakyat. Respon Kelompok Tani Makmur terhadap pelaksanaan dan pentingnya kebijakan SVLK yang belum diketahui, menyebabkan penelitian ini penting untuk dilakukan. Penelitian ini bertujuan untuk mengukur pengetahuan, sikap dan perilaku masyarakat terhadap implementasi SVLK di Kelompok Tani Makmur, Desa Totoprojo, Kecamatan Way Bungur, Kabupaten Lampung Timur pada Desember 2014.

Penelitian dilakukan dengan metode wawancara secara mendalam dan kuesioner pada 34 responden. Tingkat pengetahuan masyarakat terhadap implementasi SVLK dalam kategori baik $(82,35 \%)$, sikap masyarakat terhadap implementasi SVLK dalam kategori baik $(50,00 \%)$, dan perilaku masyarakat terhadap implementasi SVLK tidak setuju $(41,18 \%)$.
\end{abstract}

Kata kunci: Respon,Kelompok Tani Makmur, Hutan Rakyat, SVLK, Lampung Timur.

\begin{abstract}
The Capability level of knowledge about the implementation of the Timber Legality Verification System (TLVS) at this point is still very limited, as well as TLVS gains and losses for farmers TLVS community forests farmers. Tani Makmur Group response to the implementation and importance TLVS policy is not yet known, led to this important research to be done. This research aimed to measure the knowledge, attitudes and behavior towards the implementation of TLVS in Tani Makmur Group, Totoprojo Village, Way Bungur Sub District, East Lampung District in December 2014.

The research was conductedby the method of in-depth interviews and a question naire. The level of public knowledge of the implementation of TLVS is in good category (82,35\%), the public attitude towards the implementation of TLVS is in good category (50,00\%), and the disagreed behavior of people towards TLVS implementation $(41,18 \%)$.
\end{abstract}

Keywords: Response, Tani Makmur Group, Community Forests, TLVS, East Lampung. 


\section{PENDAHULUAN}

\section{Latar Belakang}

Mayoritas pemegang Izin Usaha Industri Primer Hasil Hutan Kayu (IUIPHHK) hanya mampu berproduksi $60 \%$ dari kapasitas produksinya. Kontribusi Hutan Rakyat terhadap pemenuhan bahan baku kayu di Provinsi Lampung mencapai lebih kurang 75\% yang berasal dari kayu rakyat, sisanya dipenuhi dari Hutan Kawasan/Hutan Produksi melalui Hutan Tanaman Industri (HTI) 5\%, dari luar Provinsi Lampung 15\% (Dishut Provinsi Lampung, 2010).

Sertifikasi memberikan resiko peningkatan beban ekonomi terhadap ekonomi rumah tangga petani Hutan Rakyat. Sistem Verifikasi Legalitas Kayu bertujuan untuk tata kelola hutan yang baik, namun sertifikasi seringkali dikaitkan dengan premium price bagi petani. Akibatnya terdapat kekecewaan bagi petani karena ternyata harga kayu tidak lebih baik setelah sertifikasi. Sehingga terjadi distrust terhadap sertifikasi dan beberapa asosiasi petani akhirnya menyatakan menolakan terhadap SVLK.

SVLK memastikan agar industri kayu mendapatkan sumber bahan baku dengan cara legal dari sebuah sistem pengelolaan Sumber Daya Hutan (SDH) yang lestari, yang mengindahkan aspek legalitas, pengelolaan hutan berkelanjutan (Sustainable Forest Management, SFM), dan tata kelola pemerintah yang transparan dan akuntabel. Sumber bahan baku industri kayu hampir seluruhnya diperoleh dari Hutan Rakyat.

Kesiapan dan pengetahuan tentang pelaksanaan SVLK di tingkat lokal masih sangat terbatas, begitu pula dengan keuntungan dan kerugian SVLK bagi petani lokal. Perlu dilakukan penelitian untuk mengetahui pengetahuan, sikap dan perilaku masyarakat terhadap pelaksanaan kebijakan SVLK di Kelompok Tani Makmur, Desa Totoprojo, Kecamatan Way Bungur, Kabupaten Lampung Timur.

\section{Tujuan Penelitian}

Penelitian ini bertujuan untuk :

1. Mengetahui pengetahuan masyarakat terhadap implementasi SVLK di Kelompok Tani Makmur.

2. Mengetahui sikap masyarakat terhadap implementasi SVLK di Kelompok Tani Makmur.

3. Mengetahui perilaku masyarakat terhadap implementasi SVLK di Kelompok Tani Makmur.

\section{METODE PENELITIAN}

Penelitian dilaksanakan di Kelompok Tani Makmur, Desa Totoprojo, Kecamatan Way Bungur, Kabupaten Lampung Timur pada bulan Desember 2014.

Alat yang digunakan dalam penelitian ini meliputi kamera, alat tulis, kuisioner, alat hitung (kalkulator), komputer. Objek penelitian adalah petani yang sudah mendapat izin SVLK di Kelompok Tani Makmur,Desa Totoprojo, Kecamatan Way Bungur, Kabupaten Lampung Timur. Hasil penelitian ini ditekankan pada memberikan gambaran secara objektif tentang keadaan atau peristiwa sebenarnya dari objek yang diselidiki. Dengan menggunakan metode deskiptif dalam penelitian ini diharapkan dapat mengetahui respon masyarakat terhadap implementasi SVLK. Data primer yang dikumpulkan antara lain identitas responden, kelembagaan kelompok tani, pengetahuan, sikap dan perilaku masyarakat terhadap implementasi SVLK. Data sekunder berupa data statistik, jumlah penduduk, dan kondisi lokasi penelitian yang diperoleh melalui studi pustaka. 


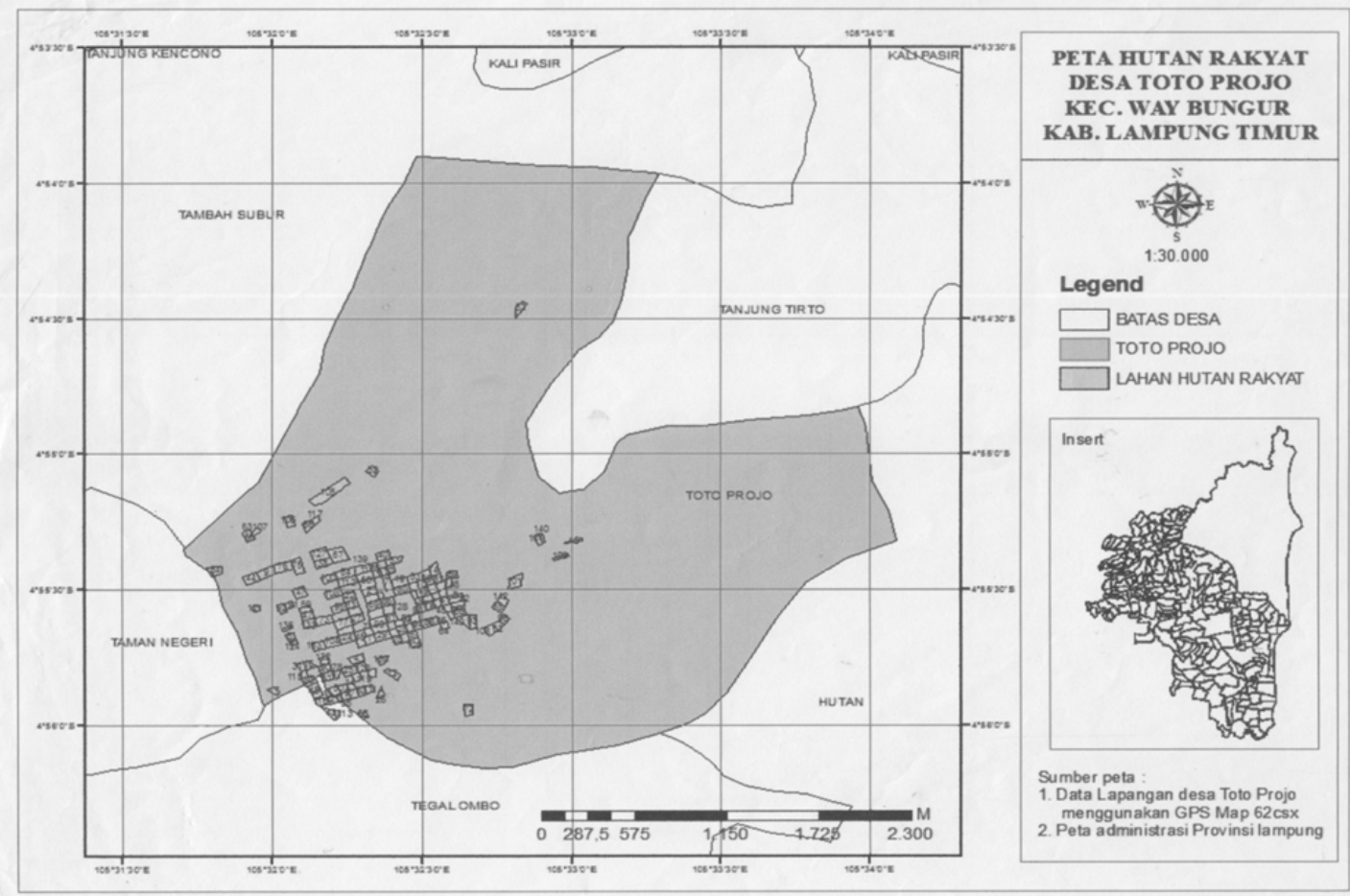

Gambar 1. Peta lokasi penelitian Desa Totoprojo Kecamatan Way Bungur Kabupaten Lampung Timur dengan skala 1:30000 (Setiawan, 2013).

Pengambilan sampel dalam penelitian ini dilakukan secara purposive sampling. Menurut Sugiyono (2010) purposive sampling yaitu pengambilan responden secara sengaja (tidak acak) yang disesuaikan dengan tujuan atau masalah penelitian dengan pertimbanganpertimbangan tertentu secara sengaja yang dalam penelitian ini adalah anggota kelompok tani yang mendapatkan izin SVLK. Jumlah petani yang mendaptkan izin SVLK sebanyak 140 orang dan yang menjadi responden penelitian sebanyak 34 responden. Jumlah responden diperoleh menggunakan rumus Rakhmat (2001).

Pengumpulan data yang dilakukan dengan menggunakan alat ukur berupa pedoman wawancara dan instrumen kuesioner yang telah disusun secara terstruktur. Pedoman wawancara digunakan untuk memperoleh data mengenai segala sesuatu yang berkaitan dengan SVLK, sementara kuesioner digunakan untuk mengukur pengetahuan, sikap dan perilaku.

Setelah data yang diperlukan berkaitan dengan penelitian terkumpul, kemudian tahapan selanjutnya adalah melakukan pengolahan data. Analisis data dalam penelitian ini menggunakan tabel tunggal, yaitu menghitung frekuensi dan membuat persentase jawaban responden pada pertanyaan kuesioner yang diajukan, dengan menggunakan rumus (Sugiyono, 2010):

$$
P=\frac{f}{n} x 100 \%
$$

Keterangan:

$\mathrm{P}=$ Persentase

$\mathrm{n}=$ Jumlah sampel

$\mathrm{f}=$ Frekuensi 
Pada angket/kuesioner ini, angka jawaban responden dimulai dari angka satu sampai tiga. Sikap, pengetahuan, dan perilaku masyarakat ini dinyatakan dalam tinjauan kontinum. Menurut Sugiyono (2010) untuk melihat pengetahuan, sikap dan perilaku masyarakat secara keseluruhan, dilakukan dengan langkah-langkah sebagai berikut:

1. Menentukan total skor maksimal : skor tertinggi $\mathrm{x}$ jumlah responden

2. Menentukan total skor minimal : skor terendah $\mathrm{x}$ jumlah responden

3. Persentase skor : (total skor : nilai maksimal) x 100

Setelah melakukan perhitungan tersebut, dilakukan interpretasi skor untuk melihat hasil persepsi dan sikap masyarakat tersebut. Berikut adalah kriteria interpretasi skor menurut Wawan dan Dewi (2010) disajikan pada Tabel 1:

Tabel 1. Kriteriainterpretasi skor pengetahuan, sikap dan perilaku.

\begin{tabular}{|c|c|}
\hline Skor & Persepsi \\
\hline $\begin{array}{l}<56 \% \\
57 \%-75 \% \\
76 \%-100 \%\end{array}$ & $\begin{array}{l}\text { Kurang } \\
\text { Cukup } \\
\text { Baik }\end{array}$ \\
\hline
\end{tabular}

Sumber : Wawan dan Dewi (2010)

Selanjutnya penentuan kategori pengetahuan, sikap dan perilaku masyarakat terhadap SVLK dilakukan dengan menggunakan rumus interval menurut Sugiyono (2010):

$$
I=\frac{N T \quad N R}{K} \quad \begin{aligned}
& \text { Keterangan } \\
& N T=\text { Nilai Tertinggi } \\
& \mathrm{NR}=\text { Nilai Terendah } \\
& \mathrm{K}=\text { Kategori } \\
& \mathrm{I}=\text { Interval }
\end{aligned}
$$

\section{HASIL DAN PEMBAHASAN}

\section{Karakteristik Responden}

Responden dalam penelitian ini adalah anggota Kelompok Tani Makmur yang telah mendapatkan sertifikasi legalitas kayu, karakteristik responden disajikan pada Tabel 2.

Tabel 2. Karakteristik responden Kelompok Tani Makmur.

\begin{tabular}{rlrr}
\hline \multicolumn{1}{c}{ No } & \multicolumn{1}{c}{ Karakteristik Responden } & Jumlah Responden & Persentase (\%) \\
\hline 1 & Umur & 0 & 0,00 \\
& $<15$ th & 30 & 88,24 \\
& $15-55$ th & 4 & 11,76 \\
& $>55$ th & & \\
& Jenjang Pendidikan Formal & 11 & 55,88 \\
& $0-9$ tahun & 22 & 41,18 \\
& $10-12$ tahun & 1 & 2,94 \\
\hline & $>12$ tahun & & \\
& Pendapatan Per Bulan & 28 & 82,35 \\
& $<1.000 .000$ & 4 & 11,76 \\
& $1.000 .000-2.000 .000$ & 2 & 5,88 \\
\hline & $>2.000 .000$ & 32 & 94,12 \\
& Luas Lahan & 2 & 5,88 \\
& $<1$ ha & 0 & 0 \\
\hline & $>3$ ha & & \\
& $>3$ ha & & \\
& & &
\end{tabular}




\begin{tabular}{llrl}
\hline 5 & Frekuensi Penyuluhan & \\
$<3$ kali & 8 & 23,53 \\
$3-5$ kali & 9 & 26,47 \\
$>6$ kali & 17 & 50,00 \\
\hline
\end{tabular}

(Data primer diolah, 2015)

\section{Tingkat Umur}

Berdasarkan Tabel 2, tingkat umur kepala keluarga responden, didominasi pada kepala keluarga yang produktif $15-55$ tahun $(88,74 \%)$, sisanya pada kepala keluarga yang tidak produktif $>55$ tahun $(11,76 \%)$, sedangkan kepala keluarga yang belum produktif tidak ada. Tingkat umur kepala keluarga responden tergolong produktif.

Hal ini mengacu pada klasifikasi umur menurut Mantra (2000), klasifikasi umur menurut produktivitasnya yakni $<1-5$ tahun (belum produktif), $15-55$ tahun (produktif), dan $>55$ tahun (tidak produktif). Umur akan sangat mempengaruhi dalam kegiatan berusaha tani. Hal tersebut berhubungan dengan kemampuan bekerja dan cara berpikir responden dalam menerima inovasi baru. Umur merupakan salah satu identitas yang dapat mempengaruhi kemampuan kerja dan pola pikir (Adhawati, 1997).

\section{Pendidikan}

Jenjang pendidikan formal responden didominasi pada pendidikan dasar 0-9 tahun $(55,88 \%)$, pendidikan menengah $10-12$ tahun $(41,18 \%)$, pendidikan tinggi $>12$ tahun $(2,94 \%)$. Jenjang pendidikan responden disajikan pada Gambar 2.

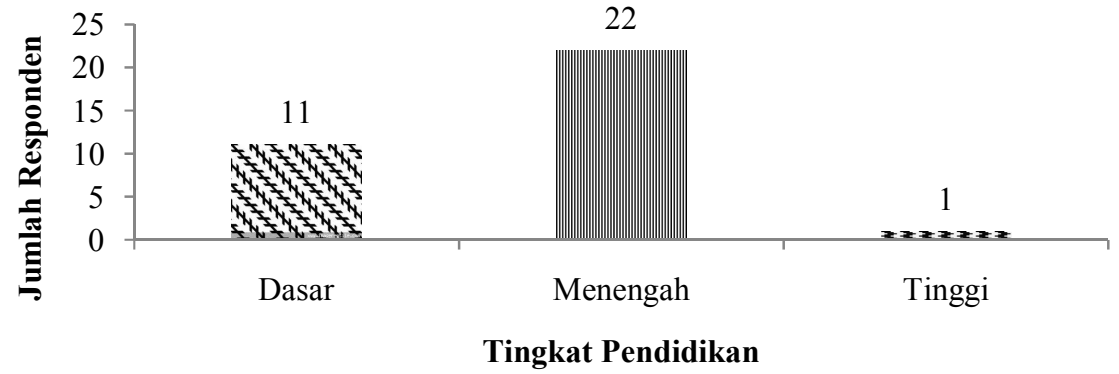

Gambar 2. Jenjang pendidikan formal responden (Data primer diolah, 2015).

Menurut UU No. 20 Tahun 2003 tentang sistem pendidikan nasional Bab I，Pasal 1, Ayat 8 yaitu jenjang pendidikan formal terdiri atas pendidikan dasar, pendidikan menengah, dan pendidikan tinggi (Direktorat Pendidikan Tinggi, 2003). Tingkat pendidikan responden relatif rendah, hal ini akan berpengaruh dalam menunjukkan tingkat pengetahuan serta wawasan petani untuk menerapkan apa yang diperolehnya untuk peningkatan usaha taninya.

Menurut Kartasapoetra (1994), mengenai tingkat pendidikan petani, dimana mereka yang berpendidikan tinggi relatif lebih cepat dalam melaksanakan adopsi inovasi. Tingkat pendidikan manusia pada umumnya menunjukkan daya kreativitas manusia dalam berfikir dan bertindak. Pendidikan rendah mengakibatkan kurangnya pengetahuan dalam memanfaatkan sumber daya alam yang tersedia.

\section{Luas lahan yang tersertifikasi dalam SVLK}

Luas lahan garapan responden Kelompok Tani Makmur berdasarkan Tabel 2, umumnya kurang dari 1 ha (94,12\%), sedangkan sisanya berkisar antara 1-3 ha (5,88\%). Hal ini menunjukkan masih banyak luas lahan garapan yang tersertifikasi dalam SVLK termasuk dalam kategori sedikit. Purwanti (2007), mengelompokkan luas lahan garapan menjadi sedikit jika luasnya kurang dari 1 ha, sedang jika luasnya 1-3 ha, dan banyak jika luasnya lebih dari 3 ha. 
Luas lahan responden yang tergolong tidak luas atau sedikit itu memungkinkan terbatasnya jumlah pohon yang akan ditanam, sehingga peluang jumlah kayu yang dipanen dan upaya pelestarian hutan juga sedikit. Keterbatasan luas lahan yang dimiliki membuat petani terbatas juga dalam menanam pohon dalam mengembangkan Hutan Rakyat (Assyh, 2014). Menurut Suhardono (2003) salah satu kendala dalam mengembangkan Hutan Rakyat adalah sempitnya pemilikan lahan sehingga pohon yang dimiliki sedikit akibatnya masih sulit untuk mewujudkan kelestarian usaha maupun kelestarian hasil hutan.

\section{Tingkat Pendapatan}

Tingkat pendapatan responden di ukur dengan 3 tingkatan yaitu di bawah Rp.1.000.000,- per bulan sebanyak 28 orang (82,35\%), responden berpendapatan dari Rp. 1.000.000,- sampai Rp. 2.000.000,- per bulan sebanyak 4 orang $(11,76 \%)$ dan responden berpendapatan lebih dari Rp. 2.000.000,- per bulan sebanyak 2 orang $(5,88 \%)$. Tingkat pendapatan responden disajikan pada Gambar 3.

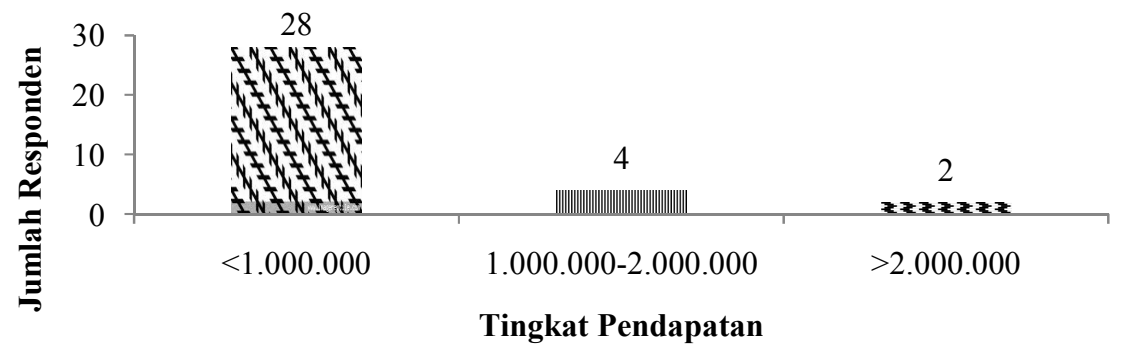

Gambar 3. Tingkat pendapatan responden (Data primer diolah, 2015).

Jumlah pendapatan yang berkisar Rp.0 - Rp 1.000.000/bulan lebih rendah apabila dibandingkan dengan Upah Minimum Provinsi (UMP) Lampung tahun 2015 sebesar Rp. 1.581.000/bulan dan Kebutuhan Hidup Layak (KHL) Kabupaten Lampung Timur sebesar Rp. 1.442.898/bulan (SKNo:G/813/III.05/2014). Kondisi yang demikian menyebabkan anggota Kelompok Tani Makmur tidak dapat memenuhi KHL, karena KHL adalah standar kebutuhan yang harus dipenuhi oleh seorang pekerja untuk dapat hidup layak baik secara fisik, non fisik dan sosial untuk kebutuhan satu bulan menurut Konfederasi Serikat Pekerja Seluruh Indonesia (KSPSI, 2014).

Pendapatan responden sebagian besar tidak diperoleh dari kegiatan di Hutan Rakyat, karena hasil dari Hutan Rakyat berupa kayu yang tidak dapat dimanfaatkan secara maksimal. Hasil Hutan Rakyat berupa kayu dimanfaatkan sebagai tabungan masa depan, atau saat kondisi yang sangat membutuhkan uang. Sehingga pendapatan responden didapat dari sawah, ladang dan ternak mereka. Menurut Triani (2009) responden memerlukan pendapatan tambahan untuk membiayai kebutuhan sehari-hari.

\section{Frekuensi Penyuluhan}

Frekuensi kehadiran penyuluhan yang diikuti responden sebanyak 17 orang (50\%) telah mengikuti kegiatan lebih dari 6 kali, 9 orang $(26,47 \%)$ telah mengikuti kegiatan sebanyak 3-5 kali, dan 8 orang (23,53\%) telah mengikuti kegiatan sebanyak 1-3 kali. Frekuensi penyuluhan disajikan pada Gambar 4.

Frekuensi penyuluhan yang diikuti responden termasuk dalam kategori tinggi. Karena keterbatasan jumlah anggota Kelompok Tani Makmur yangdapat mengikuti kegiatan penyuluhan dalam persiapan mendapatkan SVLK, maka anggota Kelompok Tani Makmur mengikutinya secara bergantian. 


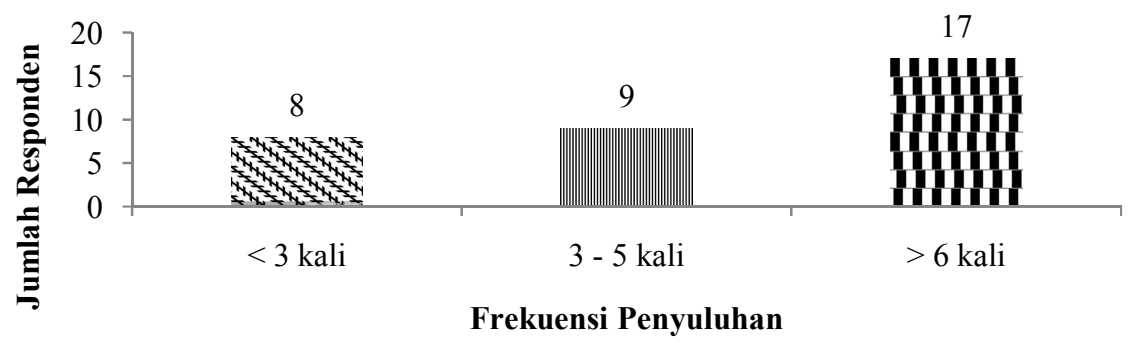

Gambar 4. Frekuensi penyuluhan responden (Data primer diolah, 2015).

Keberadaan penyuluh kehutanan merupakan salah satu ujung tombak pembangunan kehutanan di lapangan. Penyuluh kehutanan mempunyai peranan yang sangat penting dan strategis dalam mendidik dan mengajak masyarakat sekitar hutan agar mau dan mampu ikut terlibat di dalam pengelolaan hutan secara lestari (Satriani, Golar dan Ihsan, 2013).

\section{Pengetahuan responden terhadap implementasi SVLK}

Pengetahuan responden terhadap implementasi SVLK diukur berdasarkan skala likert, responden yang memiliki pengetahuan baik terhadap implementasi SVLK sebanyak 28 orang $(82,35 \%)$, responden yang memiliki pengetahuan cukup terhadap implementasi SVLK sebanyak 6 orang $(17,65 \%)$, dan responden yang memiliki pengetahuan kurang terhadap implementasi SVLK tidak ada. Pengetahuan responden terhadap implementasi SVLK disajikan pada Tabel 3.

Pengetahuan responden terhadap implementasi SVLK dikatakan baik. Hal ini menunjukkan bahwa keseriusan dalam mengikuti kegiatan penyuluhan dalam persiapan menuju SVLK sangat baik. Hal yang berpengaruh dalam pengetahuan responden terhadap implementasi SVLK adalah frekuensi penyuluhan yang tinggi, tingkat umur responden yang produktif, pekerjaan yang sebagian besar responden adalah petani, lingkungan, dan pendidikan formal yang cukup.

Tabel 3. Pengetahuan masyarakat terhadap implementasi SVLK.

\begin{tabular}{lrr}
\hline \multicolumn{1}{c}{ Pengetahuan Responden } & Jumlah Responden & Persentase (\%) \\
\hline Baik & 28 & 82,35 \\
Cukup & 6 & 17,65 \\
Kurang & 0 & 00,00 \\
\hline Jumlah & 34 & 100 \\
\hline
\end{tabular}

Sumber : Data primer diolah (2015)

Responden menyadari perlunya ikut pertemuan dalam kelompok tani dan merasa mendapatkan tambahan pengetahuan karena keterlibatannya dalam kelompok tani. Sehingga peran ketua kelompok tani dalam mengajak anggotanya sangat efektif. Pengetahuan yang didapat dari responden tentang SVLK adalah mampu mengatasi pencurian kayu, serta mampu menjual hasil kayunya ke pasar intemasional. Pengerajin kecil masih memerlukan peningkatan kapasitas pengarsipan dokumen-dokumen mereka (Magdalena, Setiadi, dan Effendi, 2013).

Faktor-faktor yang mempengaruhi pengetahuan menurut Wawan dan Dewi (2010), adalah faktor internal (pendidikan,umur, dan pekerjaan) dan faktor eksternal (lingkungan dan sosial budaya). Pada konteks Hutan Rakyat, menurut Hinrich, Muhtaman dan Irianto (2008) sertifikasi terbukti mampu meningkatkan pengetahuan dan kepedulian dalam pengelolaan sumber daya berkelanjutan pada seluruh pemangku kepentingan, bukan hanya para petani yang dilibatkan, melainkan juga pemerintah daerah dan lingkungan industri. Menurut 
Mariner, Tomey dan Faan (1989), lingkungan merupakan seluruh kondisi yang ada di sekitar manusia dan dapat mempengaruhi perkembangan dan perilaku pribadi atau kelompok.

\section{Sikap responden terhadap implementasi SVLK}

Sikap responden terhadap implementasi SVLK diukur berdasarkan skala likert, responden yang memiliki sikap baik sebanyak 17orang (50,00\%), Sikap cukup baik sebanyak 8 orang $(23,53 \%)$, dan sikap kurang baik sebanyak 9 orang $(26,47 \%)$. Sikap responden terhadap implementasi SVLK disajikan pada Tabel 4.

Tabel 4. Sikap masyarakat terhadap implementasi SVLK.

\begin{tabular}{lrr}
\hline Sikap Responden & Jumlah Responden & Persentase (\%) \\
\hline Baik & 17 & 50,00 \\
Cukup & 8 & 23,53 \\
Kurang & 9 & 26,47 \\
\hline Jumlah & 34 & 100 \\
\hline
\end{tabular}

Sumber : Data primer diolah (2015)

Sifat sikap positif yang ditunjukkan oleh responden adalah mendekati, menyenangi dan mengharapkan adanya perubahan dan peningkatan kesejahteraan hidup terhadap implementasi SVLK. Kelompok Tani Makmur sebagai penghasil kayu di Hutan Rakyat memperoleh nilai harga jual kayu yang sangat kecil dibandingkan harga beli kayu ditingkat industri, karena rantai pemasaran kayu di daerah ini sangat panjang. Hal ini menunjukan bahwa masyarakat mengharapkan nilai jual kayu ditingkat petani dapat lebih tinggi lagi, sehingga masyarakat terdorong untuk melakukan Sertifikasi Legalitas Kayu (SLK).

Hasil wawancara terhadap responden, Kelompok Tani Makmur hanya menjual kayu dari lahan mereka sendiri, apabila adanya kebutuhan yang mendadak. Responden menjual kayunya dengan harga yang murah, dan menjualnya melalui perantara atau pengepul. Harga yang didapat pada responden, tidak sesuai dengan harga pasar internasional. Mereka berharap dengan adanya sertifikasi legalitas kayu ini, dapat merubah harga kayu yang akan dijual.

Menurut Purwanto (1998) sikap dapat bersifat positif dan dapat bersifat negatif, sifat sikap positif adalah mendekati, menyenangi, dan mengharapkan objek tertentu, dan sifat sikap negatif adalah menjauhi, menghindari, membenci, dan tidak menyukai objek tertentu. Menurut Saifuddin (2001) faktor-faktor yang mempengaruhi sikap terhadap implementasi SVLK adalah pengalaman pribadi, pengaruh orang lain yang dianggap penting, pengaruh kebudayaan, lembaga pendidikan, dan faktor emosional.

Pengalaman pribadi responden sebagian besar menebang pohon tidak pada daur tertentu atau masa tebang tetapi tetap berdasarkan kebutuhan yang mendesak, menghemat biaya dan ingin mendapatkan pembayaran tunai secara cepat juga menjadi alasan petani menjual kayunya dalam bentuk pohonberdiri dan melalui perantara. Menurut Assyh (2014), penjualan kayu secara tidak langsung atau melalui perantara menyebabkan harga yang diterima di tingkat petani lebih rendah. Pengaruh orang lain yang dianggap penting dalam sertifikasi legalitas kayu di Kelompok Tani Makmur adalah dukungan dari JOFCA-JICA (Japan Overseas Forestry Consultants Association-Japan Intemational Coorporation Agency).

Meskipun dalam ketentuan Permenhut RI No.45/2012 pasal 4 ayat (4) mengharuskan setiap pemegang IUIPHHK, IUI dan TDI serta industri rumah tangga atau pengrajin dan pedagang ekspor wajib mendapatkan SLK (Sertifikasi Legalitas Kayu) dalam prakteknya hanya perusahaan besar yang berorientasi ekspor yang memiliki karena mereka adalah pihak yang membutuhkan dan mampu untuk memliki dokumen tersebut agar barang ekspor mereka dapat melewati pabean dengan mulus (Departemen Kehutanan, 2012). 
Petani hutan rakyat pada prinsipnya mendukung setiap kebijakan yang diberikan pemerintah dalam rangka mengembangkan usaha hutan rakyat. Namun jika kebijakan ini tidak memberikan keuntungan bagi Kelompok Tani Makmur bahkan membebani maka dikhawatirkan Kelompok Tani Makmur tidak dapat dan tidak mau menjalankan kebijakan tersebut (Assyh, 2014).

\section{Perilaku masyarakat terhadap implementasi SVLK}

Perilaku responden terhadap implementasi SVLK diukur berdasarkan skala likert. Perilaku responden yang setuju terhadap SVLK sebanyak 9 orang $(26,47 \%)$, responden yang ragu-ragu terhadap SVLK sebanyak 11 orang $(32,35 \%)$, responden yang tidak setuju terhadap SVLK sebanyak 14 orang $(41,18 \%)$. Perilaku Kelompok Tani Makmur terhadap implementasi SVLK disajikan dalam Tabel 5.

Tabel 5. Perilaku masyarakat terhadap implementasi SVLK.

\begin{tabular}{lrr}
\hline Perilaku Responden & Jumlah Responden & Persentase (\%) \\
\hline Baik & 28 & 82,35 \\
Cukup & 6 & 17,65 \\
Kurang & 0 & 00,00 \\
\hline Jumlah & 34 & 100 \\
\hline
\end{tabular}

Sumber : Data primer diolah (2015)

Pengetahuan dan sikap yang tinggi di Kelompok Tani Makmur tidak menghasilkan perilaku yang setuju terhadap implementasi SVLK, hal ini dimungkinkan karena pandangan masyarakat terhadap manfaat dan perkembangan implementasi SVLK belum terlihat nyata, mereka hanya memprediksi tingkat keberhasilan dari SVLK tersebut. Setelah wawancara yang dilakukan terhadap responden, sebagian besar responden berharap dengan adanya SVLK bisa memberikan peningkatan pendapatan dan kesejahteraan bagi masyarakat, dan kegiatan SVLK belum berjalan dengan semestinya. Pemanenan pohon belum dilakukan masyarakat karena belum adanya pasar yang memberikan harga kayu sesuai dengan harga standar.

Responden tidak mau dibebani dengan aturan dan biaya tambahan dalam mengusahakan Hutan Rakyat. Jika responden merasa tidak mendapat keuntungan dalam melakukan usahanya, bahkan mengalami kerugian akibat aturan-aturan dan biaya tersebut maka dapat dimungkinkan responden melakukan alih fungsi lahannya menjadi sektor lain yang lebih menguntungkan. Jika SVLK tidak dapat meningkatkan harga kayu, maka responden akan enggan untuk melaksanakannya. Munculnya suatu kebijakan harus diimbangi dengan solusi terhadap dampak dan efek dari kebijakan tersebut.

Pemberlakuan SVLK secara compulsary mengharuskan produsen dan konsumen untuk mentaatinya. Meskipun harus mengeluarkan biaya lebih untuk proses sertifikasi, keberadaan SVLK tentu akan mengangkat harga jual produk Indonesia dengan penggunaan bahan baku yang legal dan jelas. Bisnis industri kayu sangat menjanjikan dan terus berkembang seiring bisnis properti, dan memberikan kontribusi terhadap pembangunan daerah dalam penyerapan tenaga kerja (Dewi, 2014).

Keterbukaan informasi dirasa perlu untuk dilaksanakan mengingat penerapan ekolabel bukan hanya bermanfaat untuk lingkungan namun juga pada perkembangan bisnis itu sendiri. Meskipun responden diberi hak untuk menerapkan harga premium pada produknya karena telah menerapkan ekolabel, namun dalam prakteknya akan sulit dilaksanakan karena sebagian besar perusahaan belum menerapkan SVLK, sehingga konsumen akan cenderung memilih produk non ekolabel yang murah dibanding dengan produk ekolabel yang sedikit lebih mahal. Diwajibkannya SVLK sebagai salah satu syarat untuk melakukan kegiatan ekspor 
maka tidak ada pilihan baik itu produsen maupun pembeli untuk menerapkan ekolabel tersebut pada produknya dan konsumen maupun pembeli harus membeli dengan harga yang lebih mahal.

Implementasi SVLK bagi para petani, produsen dan pemerintah secara bersama-sama membuktikan kepada dunia bahwa produk furnitur Indonesia menggunakan kayu yang sah dan proses penebangannya tidak merusak lingkungan serta mempunyai asal-usul yang jelas. Fakta yang ada sekarang, secara umum kemampuan konsumen membayar lebih untuk produk bersertifikat masih di bawah kemampuan yang diperlukan oleh produsen untuk memproduksinya (Pumomo, Irawati dan Wulandari, 2011).

Menurut Amzu (2007) ada beberapa alasan yang menyebabkan perilaku masyarakat tidak sesuai dengan pengetahuan dan sikapnya. Pertama ketidaksesuaian antara sikap orang tersebut dengan informasi mengenai kenyataan sesungguhnya atau kenyataan yang terjadi. Kedua, ketidaksesuaian sikap orang tersebut dengan sikap panutannya. Ketiga, terpaksa dalam arti seseorang bersikap positif karena terpaksa takut pada kebijakan SVLK yang bersifat wajib bagi pemilik Hutan Rakyat. Tiga alasan di atas menyebabkan pengetahuan dan sikap tidak sejalan dengan perilakunya.

Para responden dalam memberikan pandangan terhadap SVLK masih dalam tingkatan memahami dan belum ikut serta melaksanakan kegiatan SVLK secara menyeluruh, selain itu munculnya pandangan negatif terhadap SVLK menunjukkan ketidaksepakatan anggota Kelompok Tani Makmur terhadap SVLK.

\section{KESIMPULAN DAN SARAN}

\section{Kesimpulan}

1. Tingkat pengetahuan responden Kelompok Tani Makmur terhadap SVLK sebanyak 28 orang $(82,35 \%)$ baik dan sebanyak 6 orang $(17,65 \%)$ cukup.

2. Sikap Kelompok Tani Makmur terhadap implementasi SVLK sebanyak 17 orang $(50,00 \%)$ baik, sebanyak 8 orang $(23,53 \%)$ cukup, dan sebanyak 9 orang $(26,47 \%)$ kurang.

3. Perilaku Kelompok Tani Makmur terhadap implementasi SVLK sebanyak 9 orang $(26,47 \%)$ setuju, sebanyak 11 orang (32,35\%) ragu-ragu, dan sebanyak 14 orang $(41,18 \%)$ tidak setuju.

\section{Saran-saran}

1. Penelitian lanjutan oleh peneliti lain diperlukan, terutama tentang efektifitas implementasi kebijakan SVLK di Hutan Rakyat.

2. Kelompok Tani Makmur harus ditingkatkan aspek pembinaan/pendampingan, pembiayaan, dan peningkatan kualitas dan kuantitas bahan baku kayu, serta mendapatkan pemasaran kayu tingkat ekspor.

3. Dinas Perkebunan dan Kehutanan Lampung Timur, DinasKehutanan ProvinsiLampung, BP2HP Provinsi Lampung dan LSM direkomendasikan menjembatani implementasi SVLK dan sosialisasi lebih lanjut setelah mendapatkan sertifikasi SVLK.

\section{Ucapan Terima Kasih}

Penulis mengucapkan terima kasih kepada Bapak Sunarto, Bapak Abdur Rahman, dan Bapak Syaiful sebagai pengurus KP-SPKP Makmur yang telah membantu penulis dalam pengumpulan data. 


\section{DAFTAR PUSTAKA}

Adhawati,S.S. 1997. Analisis ekonomi pemanfaatan lahan pertanian dataran tinggi di Desa Parigi (Hulu DAS Malina) Kabupaten Goa. Thesis. Program Pasca Sarjana Universitas Hasanudin. Makasar.

Amzu, E. 2007. Sikap Masyarakat dan Konservasi suatu analisis Kedawung (Parkia timoriana (DC) Merr.) sebagai stimulus tumbuhan obat bagi masyarakat, studi kasus di Taman Nasional Meru Betiri. Skripsi. Institut PertanianBogor. Bogor.

Assyh, N. 2014. Efektivitas implementasi kebijakan sertifikasi legalitas kayu di hutan rakyat studi kasus di Kabupaten Wonosobo Provinsi Jawa Tengah. Thesis. Program Pasca Sarjana. Institut Pertanian Bogor. Bogor.

Dewi, B.S. 2014. Kisah Pejuang Kehutanan Indonesia. Aura publishing. Bandar Lampung.

Departemen Kehutanan. 2012. Permenhut RI No. 45/2012 pasal 4 ayat 4. Jakarta

Dinas Kehutanan Provinsi Lampung. 2010. Data dan Informasi Pemasaran Hasil Hutan Kayu Provinsi Lampung Tahun 2010. Lampung.

Direktorat Pendidikan Tinggi. 2003. UU No. 20 Tahun 2003. Jakarta

Hinrichs, A., Muhtaman, D.R.,dan Irianto, N., 2008. Sertifikasi Hutan Rakyat di Indonesia. Jakarta (ID). GTZ.

Kartasapoetra, A.G. 1994. Teknologi Penyuluhan Pertanian. Bumi Aksara.Jakarta

KSPSI. 2014. Standar Kebutuhan Hidup Layak (KHL).http://kspsi.com/analisa- dandata/analisa/standar-kebutuhan-hidup-layak-khl/. diakses tanggal 1 Oktober 2015.

Magdalena., Setiadi, A., dan Effendi, R. 2013. Sistem Verifikasi Legalitas Kayu vs Lacey Act: Peluang dan Tantangan.Jurnal Policy Brief. Vol. 7(1).1-8.

Mantra, IB. 2000. Demografi umum. Pustaka Pelajar. Yogyakarta.

Mariner A;Tomey R.N;and Faan.1989. Guide to Nursing Management and Leadership. Mosby Company. USA.

Purnomo, H. Irawati, H,R. dan Wulandari, R.J. Kesiapan Produsen Mebel di Jepara dalam Menghadapi Sertifikasi Ekolabel (The Readiness inJepara Furniture Manufactured in Confront of Ecolabel Certification).Jurnal Manajemen Hutan Tropika. Vol 17(3). 127-134.

Purwanti, R. 2007. Pendapatan Petani Dataran Tinggi Sub DAS Malino Studi Kasus KelurahanGantarang, Kabupaten Gowa. Jurnal Penelitian Sosial dan Ekonomi Kehutanan. Vol. 4 (3). 257-269. Bogor.

Purwanto, H.1998. Pengantar Perilaku Manusia Untuk Keperawatan.EGC. Jakarta.

Rakhmat, J. 2001. Metode Penelitian Komunikasi. PT. Remaja Rosda Karya. Bandung.

Saifuddin, A. 2001. Sikap Manusia Teori dan Pengukurannya.edisi 2. Pustaka Pelajar. Yogyakarta.

Satriani, Golar, dan Moh. Ihsan. 2013. Persepsi Dan Sikap Masyarakat Terhadap Penerapan Program Pemberdayaan Sekitar Sub Daerah Aliran Sungai Miu (Studi Kasus Program SCBFWM Di Desa Simoro Kecamatan Gumbasa Kabupaten Sigi).Jurnal Warta rimba. Vol. 1(1). 1-9.

Setiawan, T. 2013. Peta Hutan Rakyat Desa Totoprojo Kecamatan Way Bungur Kabupaten Lampung Timur. Tidak dipublikasikan.

Sugiyono. 2010. Metode Penelitian Kuantitatif dan Kualitatif.Alfabeta R \& D. Bandung.

Suhardono. 2003. PengelolaanHutan Rakyat Di Wonosobo. Jurnal Hutan RakyatVol. 5(1). $1-8$.

Triani, A. 2009. Analisis Willingness to Accept masyarakat terhadap pembayaran jasa lingkungan DAS Cidanau. Skripsi. Fakultas Ekonomi dan Manajemen IPB. Bogor.

Wawan, A dan Dewi, M. 2010. Teori dan Pengukuran Pengetahuan, Sikap dan Perilaku Manusia. Nuha Medika.Yogyakarta 